\title{
Phlegmonous Colitis in a Patient with Liver Cirrhosis, Hepatocellular Carcinoma and Acute Promyelocytic Leukemia
}

\author{
Takahiro YAMADA $* * *$, Eizaburo SASATOMI**, Toshimi SATO** and Shigeo NAKANO**
}

\begin{abstract}
We describe a case of phlegmonous colitis occurring in a 70-year-old man with liver cirrhosis, hepatocellular carcinoma and acute promyelocytic leukemia. He developed an acute abdominal emergency and died during the first day of admission. Autopsy revealed a colon lesion characterized by suppurative inflammation associated with marked edema and hemorrhage in the submucosa. These findings were identical both macroscopically and microscopically to those of phlegmonous colitis.
\end{abstract}

(Internal Medicine 34: 542-545, 1995)

Key words: suppurative inflammation, bacteria, colon, portal hypertension

\section{Introduction}

Phlegmonous inflammation of the gastrointestinal tract is a rare but fatal complication occurring in patients with diabetes mellitus, liver cirrhosis or malignancy $(1,2)$. Phlegmonous gastritis is a well described entity (1-5), but involvement of the colon, known as phlegmonous colitis, is not well documented $(1,2,6-13)$. It is characterized by an acute suppurative process primarily involving the submucosa of the colon, and the area from the cecum to the ascending portion is much more vulnerable.

The entity seems to have remarkably decreased in recent years due to the benefit of administration of antibiotics and surgical manipulations. We demonstrate here a rare case of suppurative bowel inflammation, and discuss the vulnerable conditions and mechanisms.

\section{Case Report}

\section{Clinical summary}

A 70-year-old man, who had been followed up for liver cirrhosis and hepatocellular carcinoma in the Department of Medicine at Saga Medical School from September 1989, was admitted to the hospital in February 1994 because of an acute abdominal emergency including rectal bleeding and severe abdominal pain. He was in shock on admission. On physical examination, blood pressure was $82 / 50 \mathrm{mmHg}$; pulse, 100 beats/min; temperature, $39.2^{\circ} \mathrm{C}$.

Laboratory data were as follows:
1. Pancytopenia with an appearance of abnormal myeloid series, suggesting acute promyelocytic leukemia: $\mathrm{Hb}, 7.3 \mathrm{~g} / \mathrm{dl}$; hematocrit, 20.9\%; red cell count, $2.04 \times 10^{6} / \mathrm{mm}^{3}$; white cell count, $1,000 / \mathrm{mm}^{3}$ with $7 \%$ of myeloblasts sometimes containing Auer rods, $21 \%$ promyelocytes, $29 \%$ myelocytes and $1 \%$ abnormal lymphocytes; platelet count, $1.0 \times 10^{4} / \mathrm{mm}^{3}$.

2. Increased activity of fibrinolysis: thrombin-antithrombin complex, $86.0 \mathrm{ng} / \mathrm{ml}$ (normal $3.0 \mathrm{ng} / \mathrm{ml}>$ ) and D-dimer, 32.1 $\mu \mathrm{g} / \mathrm{ml}($ normal $1.0 \mu \mathrm{g} / \mathrm{ml}>$ ).

3. Confirmation of the presence of an inflammatory process: the test for C-reactive protein, 2+; Bacterial cultures of arterial blood and ascites were negative.

4. Liver dysfunction: serum aspartate aminotransferase, 39 IU/1; alanine aminotransferase, 27 IU/l; lactate dehydrogenase, 845 IU/l; alkaline phosphatase, 124 IU/l; cholinesterase, 324 $\mathrm{IU} / \mathrm{l}$; total protein, $4.5 \mathrm{~g} / \mathrm{dl}$ (albumin, $2.1 \mathrm{~g} / \mathrm{dl}$ ); total bilirubin, $1.7 \mathrm{mg} / \mathrm{dl}$; total cholesterol, $61 \mathrm{mg} / \mathrm{dl}$.

5. Confirmation of the presence of hepatocellular carcinoma: $\alpha$-fetoprotein, $5,478 \mathrm{ng} / \mathrm{ml}$; carcinoembryonic antigen, $3.3 \mathrm{ng} / \mathrm{ml}$; and CA 19-9, $4 \mathrm{U} / \mathrm{ml}$.

The clinical diagnosis of the abdominal symptoms was a rupture of hepatocellular carcinoma. The patient developed a severe shock and died during the first day of admission, approximately 14 hours after admission, an autopsy was subsequently carried out.

\section{Pathological findings}

At autopsy, the mucosal surface of the cecum and ascending colon was chocolate-colored with somewhat of a cobblestone

From the Departments of *Emergency Medicine and **Pathology, Saga Medical School, Saga

Received for publication September 29, 1994; Accepted for publication January 17, 1995

Reprint requests should be addressed to Dr. Takahiro Yamada, the Department of Emergency Medicine, Saga Medical School, Nabeshima 5-1-1, Saga 849 
appearance, and the wall was prominently thickened due to submucosal edema (Fig. 1a). Histologically, the submucosa showed marked edema, deposition of nuclear debris, dilatation


Figure 1. Macroscopic and microscopic features of the colon lesion. a) From the cecum (asterisk) to the ascending colon, the mucosal surface, measuring $10 \mathrm{~cm}$ in length, partly shows a cobblestone appearance. Ulceration and stenosis are not seen. b) The wall is markedly thickened due to submucosal edema associated with congestion of small blood vessels. Asterisk indicates the submucosa, hematoxylin and eosin stain: $\times 5$. c) The proper muscle layer and serosa also show inflammation (HE stain, $\times 80$ ). and congestion of blood and lymph vessels, and an associated extravasation of red blood cells (Fig. 1b). The mucosa partly showed autolysis, but ulceration was not found. Infiltration of neutrophils was slight to mild, suggesting bone marrow suppression due to acute promyelocytic leukemia. The inflammation spread to the proper muscle layer and serosa (Fig. 1c).
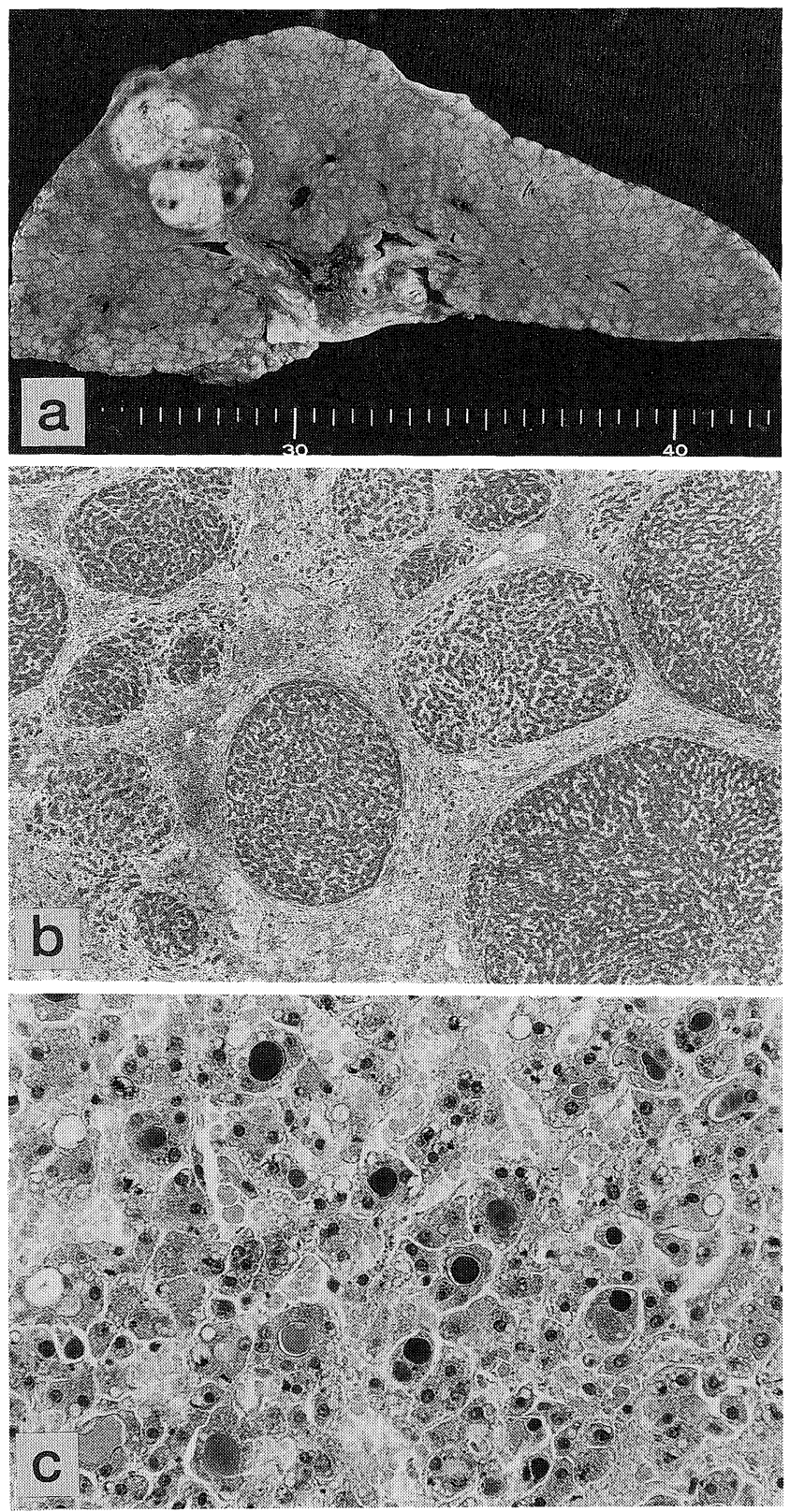

Figure 2. Macroscopic and microscopic features of the liver lesion. a) Cut surface of the liver shows diffuse formation of small nodules separated by scar tissue. In the right lobe, masses with necrosis and hemorrhage are observed. b) Regenerative nodules are separated by fibrous connective tissue (HE stain, $\times 40$ ). c) Cancer cells are arranged in pseudoglandular fashion frequently associated with bile plugs (HE stain, $\times 320)$. 
Acute inflammation was not evident in any other tissues or organs. Grossly and histologically, the liver, weighing 1,210 g, showed features of cirrhosis including disorganization of normal architecture by fibrous scar tissue, subsequent formation of micronodules, infiltration of lymphoid cells and cholestasis (Fig. 2a and b). In the right lobe of the liver, masses with necrosis and hemorrhage, measuring $5 \times 4 \mathrm{~cm}$ in the largest one, were observed (Fig. 2a). At the periphery of the masses, trabecular or pseudoglandular growth pattern of viable cancer cells was evident, and they were classified as moderately differentiated hepatocellular carcinoma (Fig. 2c). There was neither portal invasion nor distant metastasis. The bone marrow was almost totally replaced by immature blastic cells (Fig. 3), compatible with the figures of acute promyelocytic leukemia. The kidney showed formation of fibrin thrombi in capillaries of glomeruli (Fig. 4), suggesting the presence of disseminated intravascular coagulation due to acute promyelocytic leukemia.

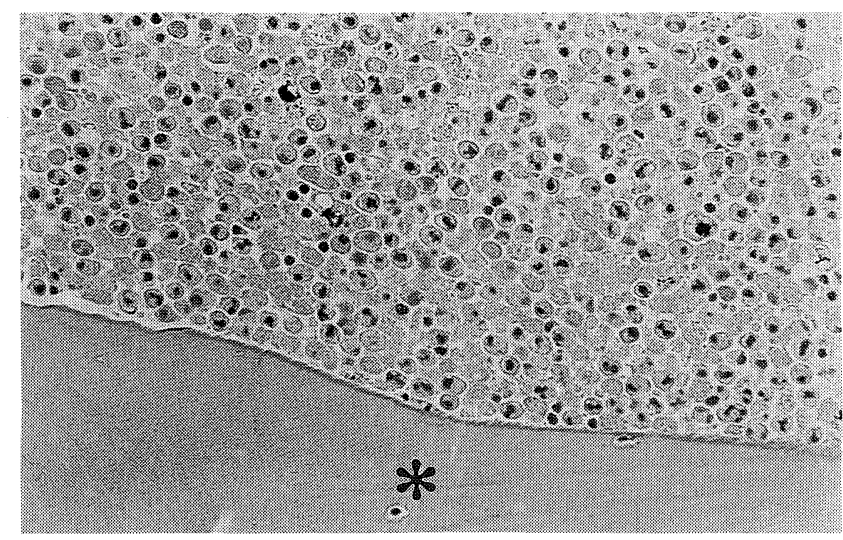

Figure 3. Light microscopy of the bone marrow. The marrow is totally replaced by atypical granulocytic cells with ample cytoplasm. Asterisk indicates bone trabecula (HE stain, $\times 320)$.

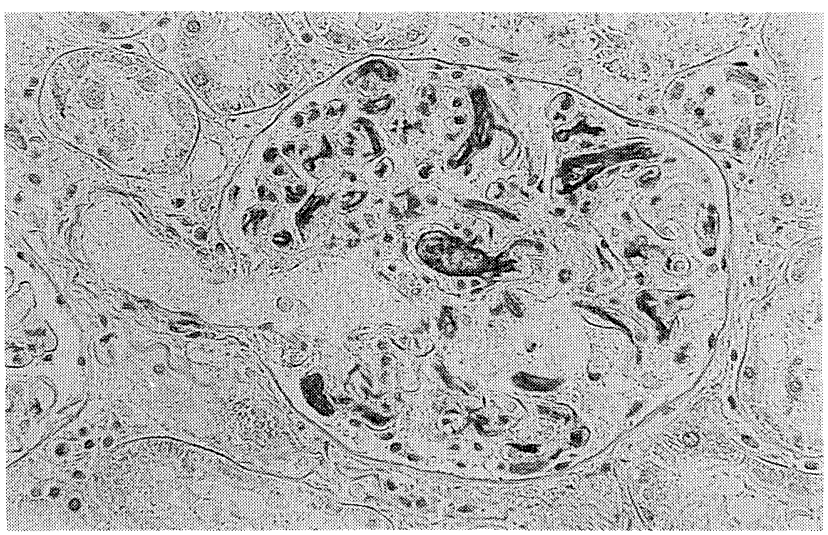

Figure 4. Light microscopy of the kidney. Glomeruli show multiple fibrin thrombi in capillaries (phosphotungstic acid hematoxylin stain, $\times 320$ ).

\section{Discussion}

Phlegmonous enterocolitis, characterized by an acute suppurative inflammatory process, is an unusual, fatal condition, and is typically diagnosed at autopsy. The mortality and morbidity have remarkably decreased in recent years. Rosen and Won (12) described eight cases of phlegmonous enterocolitis, and seven of them were found in approximately 20,000 autopsies $(0.035 \%)$. In a previous report (13), Sato examined 7,105 autopsies and reported seven cases of phlegmonous colitis $(0.099 \%)$.

Clinicopathologically, phlegmonous colitis preferentially occurs in the cecum to ascending colon or whole colon in patients with abnormal liver conditions, i.e. viral or alcoholic hepatitis or cirrhosis. In a previous report (13), seven patients with phlegmonous colitis had portal hypertension, namely, liver cirrhosis with or without foci of carcinoma in 6 and pancreas head cancer with portal emboli in 1 . In such patients, increased portal pressure and subsequent venous congestion and edema may disrupt the physiological barrier against bacterial infection. Mucosal injury was also proposed to explain the pathogenesis of the disease $(6,12)$. In all of our cases, however, mucosal injury such as ulcer and necrosis was not present. Moreover, there were no reports of phlegmonous colitis, as far as we know, associated with ulcerative colitis or Crohn's disease. We believe that the pathogenesis of this disease is attributed to the disruption of the physiological barrier against bacterial infection due to portal hypertension.

In the present case, immunosuppression due to acute promyelocytic leukemia must have played an important role to accelerate the phlegmonous inflammation.

Although we did not determine the causative bacteria with blood culture and tissue stainings, many kinds of organisms were detected with cultures of the intestinal lesions and blood or gram-stained tissue sections (1, 2, 6-13); streptococci, pneumococci, E. coli, gram-positive cocci (type unclassified), gramnegative rods (type unclassified), cocci (type unclassified), or gram-positive rods (type unclassified).

Finally, we report a rare inflammatory bowel disease; knowledge of the disease is essential to accurately differentiate the diagnosis from other acute abdominal emergency.

Acknowledgements: The authors thank Mr. F. Muto, S. Nakahara and T. Tanamachi for technical assistance. We are also grateful to Professor $\mathrm{H}$. Sugihara and Professor O. Tokunaga, Department of Pathology, Saga Medical School, for supporting this work.

\section{References}

1) Morson BC, Dawson IMP, Day DW, Jass JR, Price AB, Williams GT. Inflammatory disorders. in: Morson and Dawson's Gastrointestinal Pathology. (3rd ed), Blackwell Scientific Publications, Oxford, London, Edinburgh, Boston, Melbourne, 1990, p.534.

2) Lewin KJ, Riddell RH, Weinstein WM. Enteric infections and associated disease. in: Gastrointestinal Pathology and its Clinical Implications. Igaku-shoin, New York, Tokyo, 1992, p.1042.

3) MacLeod J. Suppurative gastritis; death; necropsy. Lancet 2: 1166, 1887.

4) Gonzalez-Crussi F, Hackett RL. Phlegmonous gastritis. Arch Surg 93: 


\section{Phlegmonous Colitis}

990, 1966.

5) LaForce FM. Diffuse phlegmonous gastritis: A rare complication of pneumococcal endocarditis. Arch Intern Med 120: 230, 1967.

6) Irwin GA, McDonald $\mathrm{S}$. Two cases of localized phlegmonous colitis. $\mathrm{Br}$ J Surg 19: 362, 1932.

7) Pollack AD, Gerber LE. Abdominal visceral lesions associated with primary disease of liver. Arch Pathol 36: 608, 1943.

8) Lucke B. The pathology of fatal epidemic hepatitis. Am J Pathol 20: 471, 1944.

9) Gerard PW. Phlegmonous colitis. Report of a case. Am J Clin Pathol 51:
$338,1969$.

10) Jacobs JK, Tapper R, Ackermann JR. Phlegmonous colitis, an abdominal catastrophe. Am Surg 39: 286, 1973.

11) Mendeloff J, Wenger J. Liver disease, phlegmonous colitis, and gramnegative sepsis. South Med J 68: 507, 1975.

12) Rosen Y, Won OH. Phlegmonous enterocolitis. Dig Dis 23: 248, 1978.

13) Sato T. A pathological study on the inflammatory lesions of the large intestine seen in autopsy cases. Keio-Igaku 67: 99, 1990 (Abstract in English). 